\title{
Trauma is not a surgical disease
}

\author{
Address to the Second International Conference on Emergency Medicine, Brisbane, \\ Australia, 28 October 1988 \\ P. LANE \\ Department of Emergency Medicine, Victoria Hospital, London, Ontario, Canada
}

It is often claimed, usually with much emphasis and conviction, that 'trauma is a surgical disease!' But think about that statement-do we define disease processes by modes of therapy? Is acute psychosis a neuroleptic disease? Is low back pain a physiotherapeutic disease? Is sigmoid volvulus an endoscopic disease?

Of course not! Trauma is the anatomical and physiological disruption caused by the transfer of energy-kinetic, thermal, electrical, etc. Our approach to addressing the problem of trauma in our society must be multidisciplinary and comprehensive. In fact I think a good case can be made that our obsession with the solely surgical management of the injured patient will not lead to measurable gains.

In the initial phases of care, trauma is definitely not a surgical disease. Both prehospital care and initial resuscitation are within the domain of emergency medicine. The incidence of significant injury, with an Injury Severity Score of greater than 15, is by some estimates more than twice that of out-of-hospital ventricular fibrillation (VF). Yet we have focused on VF as the model disease entity in which to build and evaluate our pre-hospital care systems. Trauma is more frequent, more complicated, and the potential for meaningful long-term recovery in the trauma patient is much better. We must re-evaluate our Emergency Medical Service (EMS) systems and reconfigure them with a view to the care of the trauma patient. Ambulance workers need better criteria to assess the potential for serious injury. 'Surrogate' paramedics with semi-automatic defibrillators will be of little value to the trauma patient. Systems with longer transport times need to have trained personnel to intervene to protect the airway and to begin to treat shock in the field. They need the authority to bypass local hospitals to bring injured patients to the trauma units ready and equipped to treat their patients.

In the hospital the trauma patient represents an extraordinary drain on resources. A recent survey of Ontario hospitals revealed that while more than $85 \%$ of hospitals stated they had an organized cardiac arrest team, less than $20 \%$ had a designated trauma team.

Correspondence: Dr Peter Lane, Department of Emergency Medicine, Victoria Hospital, 375 South Street, London, Ontario N6A 4GS, Canada. 
Yet trauma resuscitations involve more people, more procedures, last longer, and havg a better potential for useful outcome. The team approach to resuscitation is appropriate in both the trauma unit as well as the community hospital, and the appropriate leader of that team surely should be an emergency physician. The role demands rapid and critica $\overrightarrow{\$}$ decisions, often based on minimal data-for example the chest tube before the X-ray intubation before blood gases are available, etc. Emergency physicians with theif overview of the resuscitation are the more appropriate specialists to be making decision regarding the priorities of investigation and management. Surgeons with their organ $\bar{G}$. specific interests are not in a position to balance all considerations. Unfortunately, thi $\overrightarrow{{ }_{3}}$ model of trauma teams with emergency physicians as team leaders remains the exception rather than the rule in most of the hospitals in all of our countries.

A useful paradigm for the investigation of accidents was introduced by Haddon in: 1972. It consists of a $3 \times 3$ matrix, with columns labelled Environmental factorg్ (physical and societal), Vehicular factors, and Human factors. The rows are labelle Pre-crash, Crash, and Post-crash. I find this paradigm also most useful in the evaluatiog of trauma systems (Table 1). With this matrix we can see that the care of the injured patient will fit in to the Post-crash-Human factors cell. To focus all of our professionafi and societal energies on that cell to the exclusion of all others may help the individuat patient but will have little impact on overall outcome.

Table 1 Paradigm for the investigation of accidents

\begin{tabular}{|c|c|c|c|}
\hline & $\begin{array}{l}\text { Environmental } \\
\text { (Physical societal) }\end{array}$ & Vehicular & Human \\
\hline \multirow[t]{5}{*}{ Pre-crash } & Road design & Safety standards & Driver testing and licensing \\
\hline & Traffic streaming & Vehicle design & $\begin{array}{l}\text { Drinking and driving } \\
\text { legislation }\end{array}$ \\
\hline & Topography & Crash readiness & \\
\hline & Lighting & Restraint system & \\
\hline & EMS systems & Regulations & \\
\hline \multirow[t]{5}{*}{ Crash } & Road condition & Seat-belt use & Blood alcohol concentration \\
\hline & Lighting at time of accident & Condition of vehicle & Presence of other drugs \\
\hline & $\begin{array}{l}\text { Time of day } \\
\text { Weather conditions }\end{array}$ & $\begin{array}{l}\text { Speed travelled } \\
\text { Accident kinetics }\end{array}$ & Wakefulness of driver \\
\hline & Emergency response times & & Co-morbid conditions \\
\hline & Access to site & & $\begin{array}{l}\text { ? seizure } \\
\text { ? MI }\end{array}$ \\
\hline \multirow[t]{3}{*}{ Post-crash } & Accident investigations & Damage to vehicle & Injuries sustained \\
\hline & Follow-up & Forensic investigation & Pre-hospital care \\
\hline & Causative factors & $\begin{array}{l}\text { Need for extrication } \\
\text { from vehicle }\end{array}$ & Outcome \\
\hline
\end{tabular}


Emergency physicians are naturally oriented towards the 'front end' of care and I would like to plead that we look even a little further forward in the field of trauma. In his 1986 lecture to us in London, William Rutherford demonstrated a sterling example of this. He reported on his multicentre study evaluating the impact of the introduction of seat-belt legislation into the UK. $\mathrm{He}$ and his colleagues had enough foresight to recognize the potential for such a study and assessed injuries before and after the legislation was proclaimed, in several hospitals. This would be an example of work in the Crash-Vehicular factors cell. It was also the sort of study that allows public policy makers to see the impact of their actions on the community as a whole-a view they rarely get other than at the ballot box.

An example of Pre-crash-Human factors is the consumption of alcohol by drivers. For 2 years now at Sunnybrook Medical Centre in Toronto we have run a program entitled PARTY - an acronym for Prevent Alcohol-Related Trauma among Youth. Here, once a week we bring high school students in to the trauma unit to talk to them about drinking and driving and trauma. They meet two teenage quadriplegics and learn about life in a wheelchair. They tour the hospital, meeting, or at least viewing, injured patients in the Intensive Care Unit, the Neurosurgical Ward, the Trauma Ward, and the rehabilitation hospital nearby. The students then view a short film on the topic and engage in small group discussions and role playing exercises. As you can imagine this is a tremendously powerful program for the students. An element of drama is often added when one or two of the students in each group collapse at the sight of external fixators protruding from a pelvis or tibia. The program has received a great deal of media attention, and is presently reasonably well funded. An evaluation of the impact of the program is complicated and not yet completed.

The actual state of the driver at the time of the crash would be a Crash-Human factors issue. Dr Barry McLellan, one of our Emergency Physicians, is heading a group investigating blood alcohol and drug levels at the time of the crash. Because of the first order kinetics of alcohol, it is possible to project backwards to determine blood levels at the time of the crash from the first blood sample drawn on admission. Not surprisingly, almost $50 \%$ of drivers admitted to the Trauma Unit were legally drunk, and many more had consumed other substances-both prescription and non-prescription drugs.

The importance of this paradigm is perhaps best demonstrated in the Third World, and here I think we could as emergency physicians have a very significant role. Recently, I was invited to Guyana and Nicaragua to evaluate their EMS and trauma systems. Guyana, formerly British Guiana is a tiny country on the north coast of South America between Surinam and Venezuela. Its health care system reflects its colonial past. Formerly the world's largest supplier of bauxite, and a major supplier of many other natural resources, its economy in recent years has collapsed. It no longer has the fiscal reserves necessary to support many of the services needed, including health care. In that country, trauma is the leading cause of death-more than cancer, more than heart disease, more than infectious diseases, more than nutritional disease. The incidence of death from motor vehicle accidents is more than twice that in North America despite the fact that there are a fraction of the number of automobiles and distances travelled are miniscule by comparison $-80 \%$ of the population lives and works in Georgetown, the capital city.

The problem here is not the health care provided-not the Post-crash-Human factors 
cell. Resources are limited-there is not one functioning ventilator in the country, and $\frac{m}{3}$ paraplegics are routinely sent home without wheelchairs to lie in bed and get decubitus $\frac{\mathbb{\Phi}}{6}$ ulcers. Rather, the problems are in other cells - road design and lighting are abysmal, $z$ there are no stop lights, there are minimal vehicle safety and maintenance standards, $\stackrel{\mathbb{Q}}{\circ}$ there are no seat-belts, let along legislation and use, there is one ambulance in the whole $\overrightarrow{\bar{F}}$ country ... the list goes on.

In Nicaragua, the story is similar. This Central American country has had its public treasury drained in a war against Contras funded by the largest economy in the world. $\frac{\overline{\bar{N}}}{\overline{2}}$ All the country's resources, then, are directed away from the basic government services. $\stackrel{\mathbb{\Omega}}{\Omega}$ Again, trauma is the leading cause of death among the civilian population. Hospital care is certainly better here but still there are only three functioning ventilators in the $\vec{\odot}$ country and a continuing shortage of equipment, supplies, and medicines. On twisting mountain roads, corners are not marked by guard-rails but rather crosses commemorat- $\stackrel{\omega}{\sigma}$ ing those that have gone over the edge. Buses carry more people on them than in them $\frac{\Phi}{3}$ and they regularly fall off as the bus hurtles around the corner at 'break-neck' speeds. $\%$. The inadequacy of public transportation is most evident at rush hours when curb lanes: are jammed with hundreds of workers trying to hitchike home. Understandably, pedestrian trauma is common. So again we can see that the Post-crash-Human factors $=$ cell is not the critical area.

And what is our response as Western countries to these needs in the Third world? We spend a considerable sum in foreign aid supporting primary care clinics, immunization $\rightarrow$ and nutritional programs. Yet the leading killer here and elsewhere in the Third Worldo is trauma. The potential for saving many productive lives is there if attention we웅 directed towards vehicle standards, road design, public transit systems, driver testifigs and licensing, etc.

A final sense in which trauma is not a surgical disease is in the quantification andڤ characterization of the problem-we need a much better understanding of what sort of crashes are occurring, when, where, and why they are occurring, how many patients areö injured or killed, what sort of injuries they sustained, and what the overall cost is. $\frac{3}{5}$ Without such characterization of the problem, a true evaluation of the impact of preventative measures and legislation is not possible. In short we need trauma registries in all of our jurisdictions to provide these population-based data. And we should strive 3 . to ensure that these data are collected in such a way as to allow comparison from one jurisdiction to another. We as emergency physicians can and should play a leadership role in the design and management of such registries.

The Centres for Disease Control in Atlanta convened a consensus conference ino January of this year. Representatives and interested individuals from across the US $\supset$ were invited-surgeons, emergency physicians, epidemiologists, nurse co-ordinators, administrators ... . and two Canadians. Two busy days of meetings were held, at the end of which no consensus was achieved. A completely unwieldy data set was proposed, $N$ incorporating more than 150 data points per patient. Fortunately, subsequent revisions స్ have pared this down to 95 data points per patient in a revision I received just a fewo weeks ago.

In Canada, health is a responsibility of the provincial governments. The Trauma Association of Canada is coordinating efforts in the different provinces to develop provincial registries. In Ontario a two-tiered registry will be used-a minimal data setō 
and a comprehensive data set. The minimal data set registry will record injuries of every patient admitted to hospital as a result of injury. Information will be abstracted from that, normally completed at the time of discharge, including demographic information, time, location and cause of injury, all diagnoses, complications and procedures and outcomes. This will, for the first time, provide us with a broad population-based data base of the full impact of trauma in our province. The comprehensive data set registry will include patients from trauma units with an Injury Severity Score of greater than 15-those severely injured patients as well as coroner's information on those who have died. This data set will be very similar to the CDC data set, and include much more information about the causes of the accident, details of pre-hospital care and outcome. Similar and comparable registries will be developed in other provinces. Soon we should be able to characterize and quantify the trauma problem in Canada reliably.

In summary, trauma is much more than a surgical disease, and this approach has in my view hampered our ability to address the problem. There is a real need for leadership on the issue, both nationally and internationally, and I can think of no better group to provide that than emergency physicians.

\section{REFERENCES}

Haddon W. J. (1972) Trauma is not a surgical disease. fournal of Trauma 12, 193-9. 